\title{
Minireview
}

\section{Does the Gut Microbiota Modulate Host Physiology through Polymicrobial Biofilms?}

\author{
Jiayue Yang ${ }^{1,2}$, Yongshou Yang ${ }^{1 \dagger}$, Manami IshiI ${ }^{1,2 \dagger}$, Mayuko NaGata ${ }^{1,3 \dagger}$, WanPing Aw ${ }^{1,2}$, Nozomu Obana ${ }^{4}$, \\ Masaru Tomita ${ }^{1,2,3}$, Nobuhiko Nomura ${ }^{5,6}$, and Shinji FuKUdA ${ }^{1,2,4,7,8 *}$ \\ ${ }^{1}$ Institute for Advanced Biosciences, Keio University, 246-2 Mizukami, Kakuganji, Tsuruoka, Yamagata 997-0052, Japan; \\ ${ }^{2}$ Systems Biology Program, Graduate School of Media and Governance, Keio University, 5322 Endo, Fujisawa, Kanagawa 252- \\ 0882, Japan; ${ }^{3}$ Faculty of Environment and Information Studies, Keio University, 5322 Endo, Fujisawa, Kanagawa 252-0882, \\ Japan; ${ }^{4}$ Transborder Medical Research Center, University of Tsukuba, 1-1-1 Tennodai, Tsukuba, Ibaraki 305-8575, Japan; \\ ${ }^{5}$ Microbiology Research Center for Sustainability, University of Tsukuba, 1-1-1 Tennodai, Tsukuba, Ibaraki 305-8572, Japan; \\ ${ }^{6}$ Faculty of Life and Environmental Sciences, University of Tsukuba, 1-1-1 Tennodai, Tsukuba, Ibaraki 305-8575, Japan; \\ ${ }^{7}$ Intestinal Microbiota Project, Kanagawa Institute of Industrial Science and Technology, 3-25-13 Tonomachi, Kawasaki-ku, \\ Kawasaki, Kanagawa 210-0821, Japan; and ${ }^{8}$ Metabologenomics, Inc., 246-2 Mizukami, Kakuganji, Tsuruoka, Yamagata 997- \\ 0052, Japan
}

(Received March 27, 2020_-Accepted May 30, 2020_Published online July 4, 2020)

Microbes inhabit various environments, such as soil, water environments, plants, and animals. Humans harbor a complex commensal microbial community in the gastrointestinal tract, which is known as the gut microbiota. The gut microbiota participates not only in various metabolic processes in the human body, it also plays a critical role in host immune responses. Gut microbes that inhabit the intestinal epithelial surface form polymicrobial biofilms. In the last decade, it has been widely reported that gut microbial biofilms and gut microbiota-derived products, such as metabolites and bacterial membrane vesicles, not only directly affect the host intestinal environment, but also indirectly influence the health of the host. In this review, we discuss the most recent findings from human and animal studies on the interactions between the gut microbiota and hosts, and their associations with various disorders, including inflammatory diseases, atopic dermatitis, metabolic disorders, and psychiatric and neurological diseases. The integrated approach of metabologenomics together with biofilm imaging may provide valuable insights into the gut microbiota and suggest remedies that may lead to a healthier society.

Key words: gut microbiota, metabolite, gut microbiota-host interaction, biofilm

Microbes inhabit numerous environments, including soil, water environments, plants, and animals. Humans host various complex commensal microbe communities in and on their bodies, such as the oral microbiota, skin microbiota, and gut microbiota (The Integrative HMP Research Network Consortium, 2019). Although there are up to 37 trillion cells in the human body, approximately 40 trillion gut microbes inhabit the gastrointestinal tract (Sender et al., 2016). The host employs a number of mechanisms to maintain intestinal homeostasis and prevent anomalous immune responses directed against the microbiota. One of these protective mechanisms involves a mucus layer that covers the epithelial surface of the colon, which functions as a barrier and separates epithelial cells from gut microbes (Tropini et al., 2017) (Fig. 1A). The mucus layer prevents pathogens from reaching and persisting on intestinal epithelial surfaces and, thus, it is an important component of host immunity. This layer is constantly renewed and acts as a trap for both

\footnotetext{
* Corresponding author. E-mail: sfukuda@sfc.keio.ac.jp; Tel: +81-235-29-0528; Fax: +81-235-29-0574.

$\dagger$ Y. Y., M. I., and M. N. contributed equally to this review.
}

Citation: Yang, J., Yang, Y., Ishii, M., Nagata, M., Aw, W., Obana, N., et al. (2020) Does the Gut Microbiota Modulate Host Physiology through Polymicrobial Biofilms?. Microbes Environ 35: ME20037. https://doi.org/10.1264/jsme2.ME20037 commensal residents and pathogens, preventing their access to the epithelium (Johansson et al., 2014; Desai et al., 2016). The gut microbiota is present in different microhabitats and metabolic niches in the mucus layer secreted from the gut, the mucosa, and the surfaces of digestive residues in the gut lumen (Macfarlane and Dillon, 2007). There are several indications that gut microbes inhabit the colonic mucus as a polymicrobial biofilm, which is an extracellular matrixenclosed aggregate form of microbes (Hooper and Gordon, 2001; Sonnenburg et al., 2004; Flemming et al., 2016). Bacteria in biofilms cooperate or compete with each other and form complex communities (Tytgat et al., 2019). Healthy mucosal biofilms benefit the host because they are involved in the exchange of nutrients on the epithelial surface, increase colonization resistance, and protect the host from invasion by intestinal pathogens (Hooper and Gordon, 2001; Sonnenburg et al., 2004). The disruption of healthy mucosal biofilms leads to the nearby or direct contact of pathogenic invasive biofilms with colonic epithelial cells, resulting in inflammation (Swidsinski et al., 2005; Dejea et al., 2014; Desai et al., 2016) (Fig. 1B).

Gut microbes were initially discovered by Antonie van Leeuwenhoek (Dobell, 1932), and various species of gut microbes were subsequently identified (Table 1). In the past 15 years, the development of next-generation sequencing technology has markedly contributed to knowledge pertain- 


\section{A}
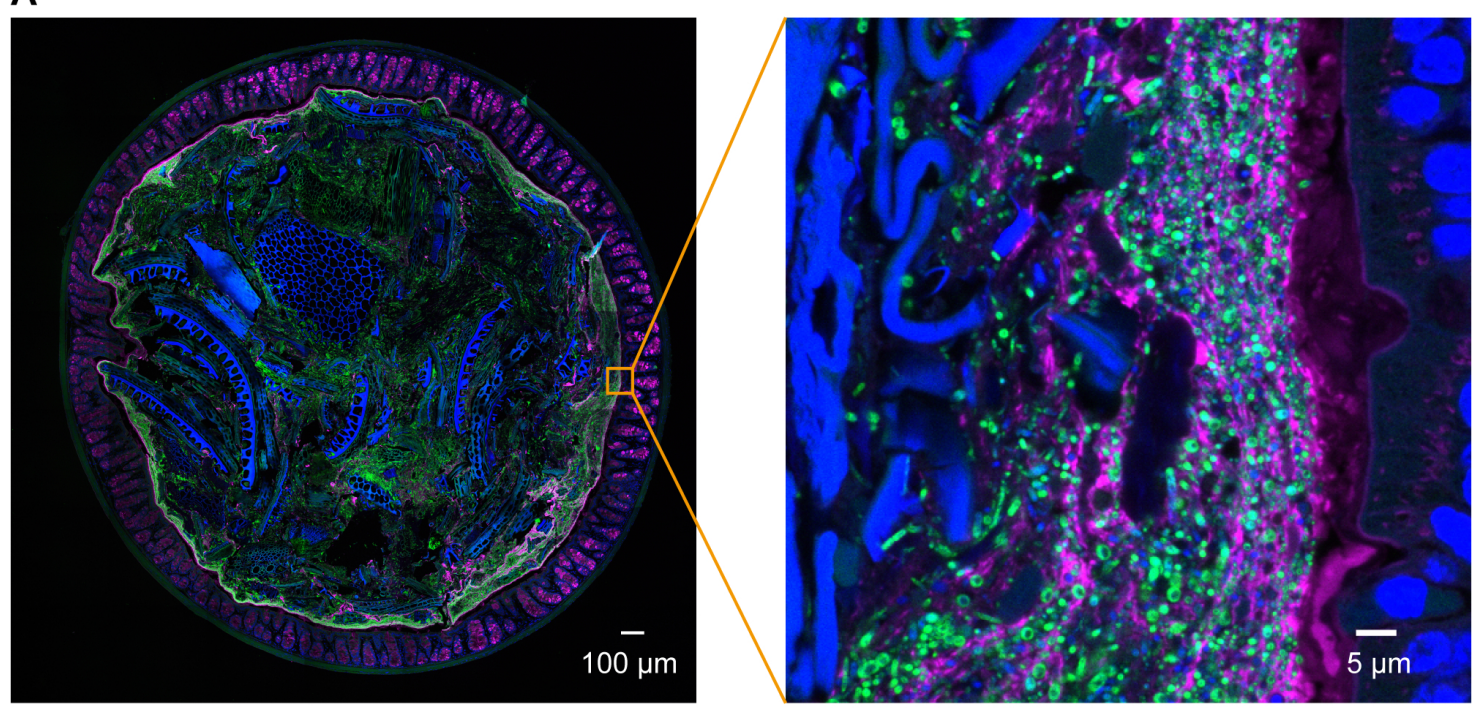

B

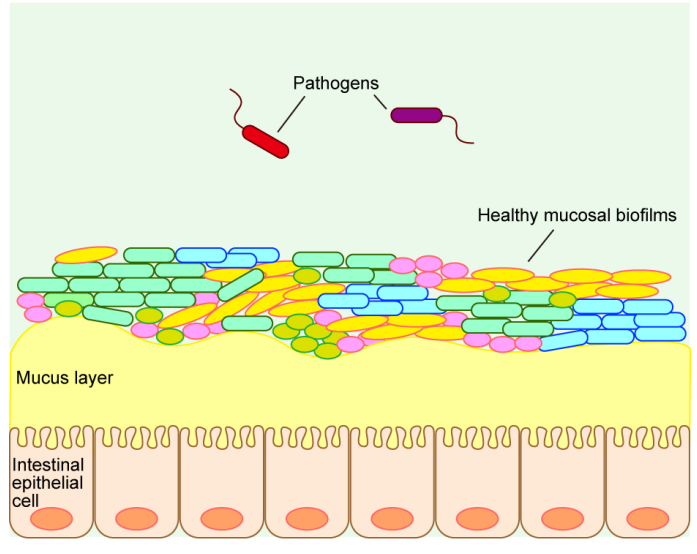

Healthy state

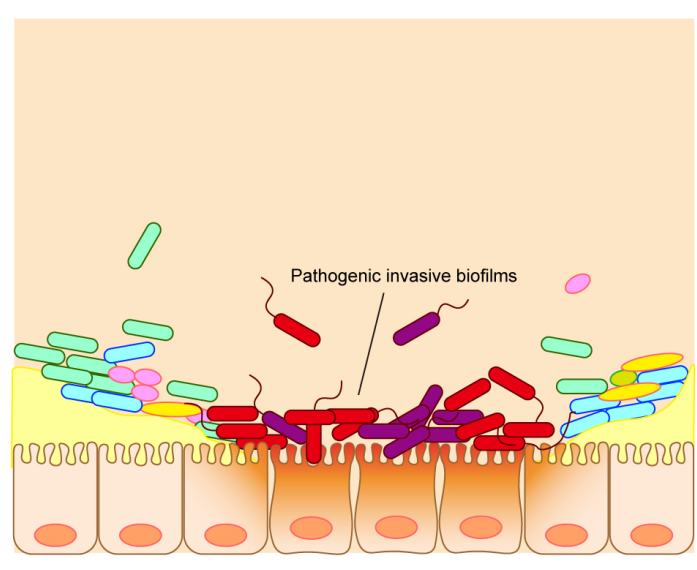

Inflamed state

Fig. 1. The interaction of gut microbial biofilms with the host. (A) Confocal microscopy fluorescent in-situ hybridization (FISH) images of the whole distal colon (left) and enlarged images of the epithelial surface (right). Blue: DNA stained with DAPI and the autofluorescence of dietary fibers; green: bacteria stained with the FAM-labeled Eub338 FISH probe; magenta: mucus stained with Alexa555-conjugated wheat germ agglutinin lectin. (B) Schematic images of healthy mucosal biofilms and the inflamed condition. In the healthy state, gut microbes inhabit colonic mucus as a polymicrobial biofilm (Hooper and Gordon, 2001; Sonnenburg et al., 2004). In the inflamed state, colonic pathogens (red, purple) form pathogenic invasive biofilms in direct contact with colonic epithelial cells (Swidsinski et al., 2005; Dejea et al., 2014; Tytgat et al., 2019). The left figure of part A was adapted with permission from Yodosha (Fukuda, 2019). The right figure of part A is the original photograph from our laboratory.

ing to the gut microbiome (Table 1). The gut microbiota in healthy adults consists of four main phyla: Actinobacteria, Bacteroidetes, Firmicutes, and Proteobacteria (Fukuda and Ohno, 2014). Gut microbiome profiles vary among individuals, and these profiles may be classified into three "enterotypes" (Arumugam et al., 2011). However, recent studies have suggested that the human gut microbiome has gradients of dominant taxa rather than discrete enterotypes and its profile may be influenced by lifestyle (Knights et al., 2014). In addition, the gut microbiota interacts with the host, crosstalks with the host immune system, and not only directly affects the host intestinal environment, it also indirectly affects the health of the host (Fukuda and Ohno, 2014; Tytgat et al., 2019). Pathogen- and microbial-associated molecular patterns (PAMPs and MAMPs, respectively; e.g., lipopolysaccharide [LPS], peptidoglycans, and flagellin from bacterial cells) and metabolites produced by the gut microbiota are the key players that shape our immune system during these interactions (Levy et al., 2017) (Table 2).

\section{MAMP- and metabolite-mediated gut microbiota-host interactions}

Gut microbes interact with the host via gut microbederived products (Levy et al., 2017). Gut microbe-derived MAMPs are recognized by pattern recognition receptors (PRRs), such as toll-like receptors (TLRs) and nucleotidebinding oligomerization domain-like receptors (NLRs), on epithelial cells (Cani, 2018). TLRs are transmembrane proteins that localize to the host cell surface, whereas NLRs are cytosolic proteins (Cani, 2018). A stimulation from gut commensal microbes shapes and trains the immune system. 
Table 1. Chronology of milestones in gut microbiota research

\begin{tabular}{|c|c|c|}
\hline Year & Event & Reference \\
\hline $1670 \mathrm{~s} \sim 1680 \mathrm{~s}$ & Discovery of gut microbes by Antonie van Leeuwenhoek & Dobell, 1932 \\
\hline 1849 & Discovery of segmented filamentous bacteria (SFB) & Leidy, 1849 \\
\hline 1885 & Discovery of Escherichia coli & Escherich, 1885 \\
\hline 1900 & Discovery of Bifidobacterium bifidum & Tissier, 1900 \\
\hline 1900 & Discovery of Lactobacillus acidophilus & Moro, 1900 \\
\hline 1953 & Discovery of the DNA double helix structure & Watson \& Crick, 1953 \\
\hline 1969 & Establishment of the culture method of intestinal anaerobes & Mitsuoka et al., 1969 \\
\hline 1975 & Invention of the sequencing method & Sanger \& Coulson, 1975 \\
\hline 1987 & Invention of the PCR method & Mullis \& Faloona, 1987 \\
\hline 1990 2003 & Human genome project & $\begin{array}{l}\text { International Human Genome Sequencing } \\
\text { Consortium, } 2004\end{array}$ \\
\hline 1991 & Proposal of the classification of bacteria by $16 \mathrm{~S}$ rRNA sequences & Weisburg et al., 1991 \\
\hline 2004 & Sargasso Sea environmental genome sequencing project & Venter et al., 2004 \\
\hline 2005 & Launched the first next-generation sequencer GS20 (454 Life Sciences) & Voelkerding et al., 2009 \\
\hline 2006 & Study on the relationship between obesity and the gut microbiome & Turnbaugh et al., 2006 \\
\hline 2007 & Metagenomic sequencing of the Japanese gut microbiome & Kurokawa et al., 2007 \\
\hline 2007 & Metabolomic study on metabolites of $E$. coli & Ishii et al., 2007 \\
\hline 2008 2014 & Human microbiome project & $\begin{array}{l}\text { Human Microbiome Project Consortium } \\
\text { (2012) }\end{array}$ \\
\hline 2009 & Discovering the induction of Th17 differentiation by SFB & Ivanov et al., 2009 \\
\hline 2010 & Proposing the concept of "Enterotypes" & Arumugam et al., 2011 \\
\hline 2011 & $\begin{array}{l}\text { Discovering the anti-infection ability of Bifidobacterium upon the E. coli } \mathrm{O} 157 \\
\text { strain through acetate }\end{array}$ & Fukuda et al., 2011 \\
\hline 2013 & Discovering that SCFAs regulate colonic Treg cell homeostasis & Smith et al., 2013 \\
\hline 2013 & $\begin{array}{l}\text { Discovering the colonic Treg differentiation induction ability of Clostridia-derived } \\
\text { SCFA butyrate }\end{array}$ & Furusawa et al., 2013 \\
\hline 2013 & $\begin{array}{l}\text { Proposal of fecal microbiota transplantation treatment for Clostridium difficile } \\
\text { infection }\end{array}$ & van Nood et al., 2013 \\
\hline 2014 2019 & Integrative human microbiome project & iHMP Research Network Consortium, 2019 \\
\hline
\end{tabular}

Table 2. Well-used acronyms in this study

\begin{tabular}{ll}
\hline Abbreviation & Full name \\
\hline ACVD & atherosclerotic cardiovascular disease \\
AD & Atopic dermatitis \\
ASD & Autism spectrum disorder \\
AZD & Alzheimer's disease \\
CRC & colorectal cancer \\
ETBF & enterotoxigenic strains of B. fragilis \\
FAP & familial adenomatous polyposis \\
GLP-1 & glucagon-like peptide-1 \\
IBD & inflammatory bowel disease \\
MAMPs & microbial-associated molecular patterns \\
MVs & membrane vesicles \\
NF-kB & nuclear factor- $\kappa$ B \\
PAMPs & pathogen-associated molecular patterns \\
PD & Parkinson's disease \\
PRRs & pattern recognition receptors \\
PSA & polysaccharide A \\
SCFAs & short-chain fatty acids \\
SFB & segmented filamentous bacteria \\
T2D & type 2 diabetes \\
TLRs & Toll-like receptors \\
TMAO & trimethylamine N-oxide \\
\hline
\end{tabular}

MAMPs are recognized by PRRs and induce adaptive responses by the immune system, resulting in the memory effect of innate immune cells and enhancements in the immune defenses of the host (Quintin et al., 2012; Saeed et al., 2014; Netea et al., 2016). Although the immune stimulation by MAMPs has been extensively examined, this stimulation may also be caused by another type of microbederived substance called bacterial membrane vesicles
(MVs). Bacterial MVs are "bubble"-like membrane structures released by bacteria that range between 20 and $400 \mathrm{~nm}$ in diameter (Toyofuku et al., 2019). Many gut microbes and pathogens have been reported to produce MVs (Shen et al., 2012; Obana et al., 2017; Canas et al., 2018; Chelakkot et al., 2018). Bacteroides fragilis is a commensal microbe in the human gastrointestinal tract that produces a type of capsular exopolysaccharide called polysaccharide A (PSA), which has an immunomodulatory function. PSA was previously shown to be effective in animal models of inflammatory bowel disease (IBD) and multiple sclerosis (Shen et al., 2012). PSA is carried by the MVs of $B$. fragilis and is delivered to the host immune system to promote regulatory T-cell (Treg) activity and anti-inflammatory cytokine production through TLR2 (Shen et al., 2012) (Fig. 2). In addition, Akkermansia muciniphila-derived MVs are present at higher amounts in healthy individuals than in patients with type 2 diabetes (T2D). The administration of $A$. muciniphiladerived MVs ameliorated T2D in a mouse model by enhancing the tight-junction function of epithelial cells, which act as a barrier and reduce gut permeability (Chelakkot et al., 2018) (Fig. 2).

The development of metabolome analysis technologies has allowed us to understand that host-gut microbe interactions occur not only via microbe-derived substances, but also through various microbial metabolites, such as trimethylamine N-oxide (TMAO), secondary bile acids, and short-chain fatty acids (SCFAs) (Fukuda and Ohno, 2014). TMAO is produced by gut microbes from dietary phosphatidylcholine and promotes atherosclerosis (Wang et al., 2011). Bile acids are synthesized in the liver, secreted into the 


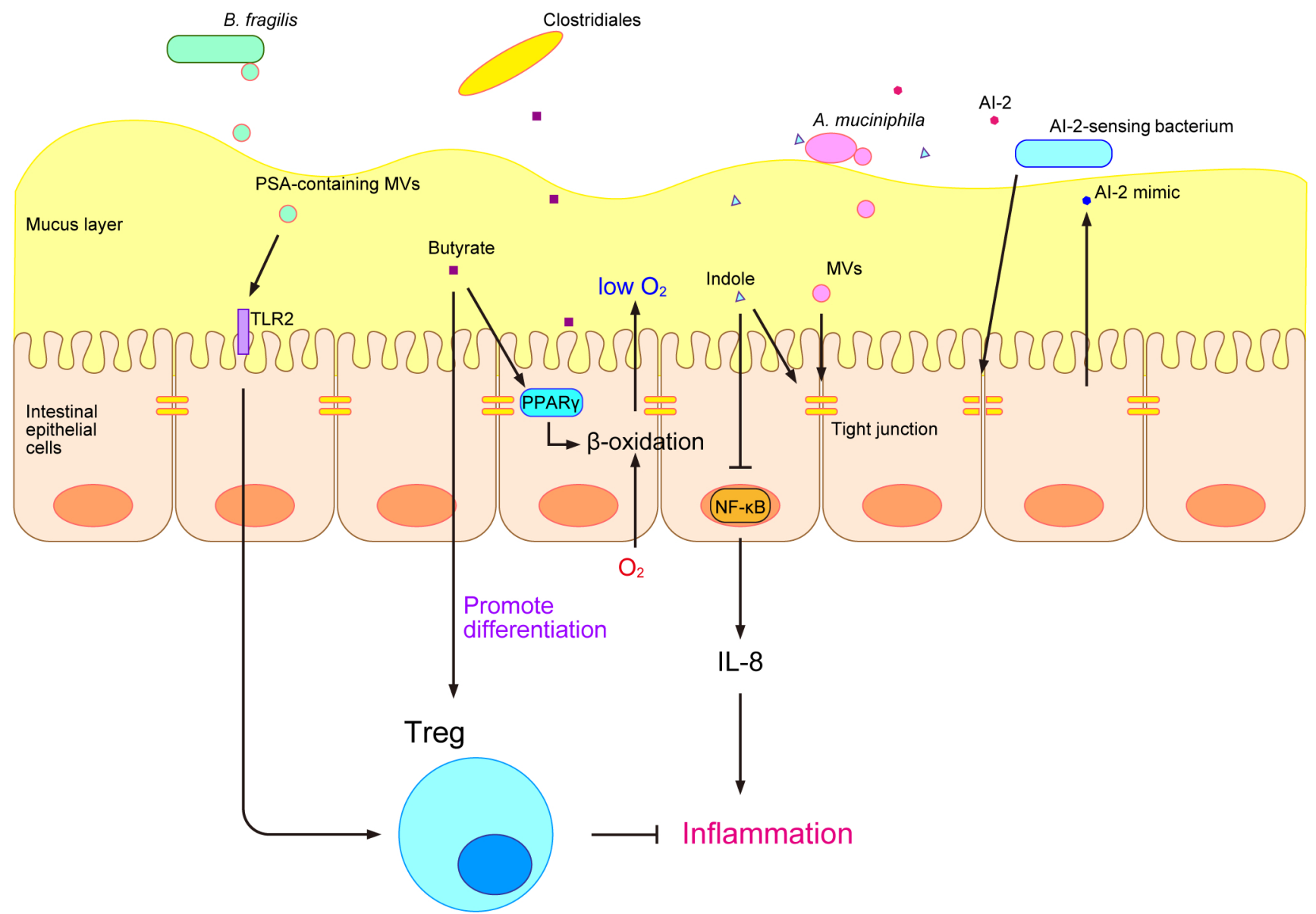

Fig. 2. Schematic illustration depicting recently reported gut microbiota-host interactions in the intestinal epithelial surface. Bacteroides fragilis produce PSA and release it through OMVs, which promote Treg activity and anti-inflammatory cytokine production through TLR2 (Shen et al., 2012). Akkermansia muciniphila-derived MVs ameliorate T2D in a mouse model by enhancing tight-junction function, thereby reducing gut permeability (Chelakkot et al., 2018). Clostridiales produce butyrate and induce the differentiation of colonic Treg (Furusawa et al., 2013). Butyrate also maintains the anaerobic environment in the colon by activating $\beta$-oxidation through PPAR $\gamma$ and consequently protecting the host from pathogenic proteobacteria (Byndloss et al., 2017). The bacterial signaling molecule indole works as an interkingdom communication signal and increases tight-junction resistance while decreasing nuclear factor- $\mathrm{KB}(\mathrm{NF}-\mathrm{\kappa B})$ and the proinflammatory chemokine interleukin-8 (IL-8) in epithelial cells in vitro (Bansal et al., 2010). Epithelial cells sense the disruption of tight junctions by bacteria and produce a molecule that mimics the bacterial signaling molecule AI-2, which may be detected by the bacterial AI-2 receptor and activates gene regulation controlled by AI-2 signaling (Ismail et al., 2016).

lumen of the small intestine, and facilitate the emulsification and absorption of lipids (Jia et al., 2018). Gut microbes convert bile acids into various secondary bile acids, which have been reported to exert inflammatory and carcinogenic effects (Jia et al., 2018). SCFAs, such as propionate, lactate, and butyrate, have been extensively examined and perform various functions in the host (Brown et al., 2003; Furusawa et al., 2013; Okada et al., 2013; Smith et al., 2013; Byndloss et al., 2017). Propionate and other SCFAs activate the orphan G protein-coupled receptors GPR41 and GPR43 and affect host energy metabolism through intestinal peptides, such as glucagon-like peptide-1 (GLP-1) (Brown et al., 2003). We previously showed that lactate induced the turnover of colonic epithelial cells in mice that were fed after starvation and promoted tumorigenesis in the colon (Okada et al., 2013). Furthermore, butyrate was shown to have an immunomodulatory function in a mouse model and induced the differentiation of colonic Treg (Furusawa et al., 2013) (Fig. 2). It also suppressed the growth of Enterobacteriaceae and protected the murine gut from Salmonella and
Escherichia coli infections by activating $\beta$-oxidation and limiting luminal oxygen levels through the intracellular butyrate sensor peroxisome proliferator-activated receptor $\gamma$ (PPAR $\gamma$ ) (Byndloss et al., 2017) (Fig. 2). To obtain a more detailed understanding of the relationship between the gut microbiome and gut metabolites, we developed an integrated omics analysis called metabologenomics, which is a method that includes both microbiome and metabolome analyses (Ishii et al., 2018). This metabologenomic approach enables us to examine the complex network among the gut microbiota, gut microbiota-derived metabolites, and the host, thereby providing more comprehensive information about the gut environment (Ishii et al., 2018). An analysis of the localization of various gut microbes in polymicrobial biofilms may provide novel insights into the metabolic network in the gut environment because previous studies suggested that gut microbes engage in cross-feeding in the gut environment (Belenguer et al., 2006; Bunesova et al., 2018; Pareek et al., 2019), and biofilms are one of the locations at which cross-feeding occurs (Sztajer et al., 2014; 
Sakanaka et al., 2015).

In addition to microbial metabolites, bacterial cell-to-cell signaling molecules are also involved in interactions with the host. Bacteria produce several types of cell-to-cell signaling molecules for intraspecies and interspecies communication and regulate their gene expression and behavior (Yang et al., 2017a; Mukherjee and Bassler, 2019). The tryptophan metabolite indole is a major signaling molecule that is produced by various gut microbes and is involved in bacterial interspecies communication as well as interkingdom communication between the host and gut microbes (Jaglin et al., 2018). Indole increases the expression of genes involved in the function of the colonic mucosal barrier and in mucin secretion and increases tight-junction resistance while decreasing nuclear factor- $\kappa \mathrm{B}(\mathrm{NF}-\kappa \mathrm{B})$ and the proinflammatory chemokine interleukin-8 (IL-8) in epithelial cells in vitro (Bansal et al., 2010) (Fig. 2). Short-term exposure to indole promotes GLP-1 secretion by mouse colonic $\mathrm{L}$ cells through the inhibition of $\mathrm{K}^{+}$channels, whereas long-term exposure decreases its secretion by blocking NADH dehydrogenase (Chimerel et al., 2014). Autoinducer-2 (AI-2) is another cell-to-cell signaling molecule that modulates virulence production, biofilm formation, and gut colonization (Thompson et al., 2015). Its production has been reported in many bacteria, including various gut microbes (Thompson et al., 2015). AI-2 signaling has both interspecies and interkingdom communication functions. Notably, in the interspecies signaling of gut microbes, Blautia obeum has been suggested to protect the murine gut from Vibrio cholerae infection through AI-2 signaling (Hsiao et al., 2014). AI-2 may also alter the composition of the gut microbiota in antibiotic-treated mice and increase the abundance of Firmicutes, one of the major phyla of gut microbes (Thompson et al., 2015). In gut interkingdom signaling, epithelial cells sense the disruption of tight junctions by bacteria and produce a molecule that mimics AI-2, which may be detected by the bacterial AI-2 receptor and activates gene regulation controlled by AI-2 signaling (Ismail et al., 2016) (Fig. 2). Previous studies revealed that AI-2 signaling modulated biofilm formation by gut microbes in vitro (González Barrios et al., 2006; Đapa et al., 2013; Laganenka and Sourjik, 2018); therefore, the host appears to use AI-2 signaling to maintain the composition of its mucosal biofilms.

\section{Gut microbiota and host health}

Gut microbiota and gastrointestinal tract infection and inflammation

The gut microbiota maintains homeostasis in the gastrointestinal tract, and the disruption of this balance results in infection and inflammation (Levy et al., 2017). We previously demonstrated that Bifidobacterium longum subsp. longum JCM $1217^{\mathrm{T}}$ produced acetate and protected host mice from E. coli O157:H7 infection by up-regulating gut epithelial barrier function to block the translocation of the Shiga toxin from the gut lumen into the blood (Fukuda et al., 2011). In addition, Clostridiales contributed to resistance to pathogen colonization and protected neonatal mice from infection (Kim et al., 2017b). In gnotobiotic mice, the restriction of dietary fiber decreased the nutrient supply to the colon, promoted the growth of mucin-degrading $A$. muciniphila, and reduced the thickness of the colonic mucus barrier, which resulted in easy access and infection by the mucosal pathogen Citrobacter rodentium (Desai et al., 2016).

IBD encompasses a group of autoimmune diseases in the gastrointestinal tract and mainly consists of Crohn's disease and ulcerative colitis. The gut microbiota is related to IBD; the transition from symbiosis to dysbiosis in the gut results in gastric chronic inflammation (Nagao-Kitamoto and Kamada, 2017). Various species have been reported to cause inflammation. Although commensal B. fragilis is considered to be beneficial for IBD, enterotoxigenic strains of $B$. fragilis (ETBF) have been detected in the stools of $13.3 \%$ of IBD patients versus $2.9 \%$ of control groups (NagaoKitamoto and Kamada, 2017). ETBF produce toxins that bind to colonic epithelial cells, disrupt E-cadherin and the mucosal barrier, and increase IL-8 production, which results in inflammation (Nagao-Kitamoto and Kamada, 2017). Microscopic observations of gut samples from IBD patients revealed invasive biofilms abundant with $B$. fragilis covering the entire mucosa and in epithelial crypts (Swidsinski et al., 2005). Furthermore, colonization of the colon by the oral pathogen Klebsiella pneumoniae resulted in IBD (Atarashi et al., 2017). K. pneumoniae colonization results in the accumulation of T helper 1 (Th1) cells and a colitis phenotype in gnotobiotic mice. Furthermore, a metagenomic data analysis showed that Klebsiella was significantly more abundant in the feces of IBD patients, which provides further support for the involvement of this pathogen in the pathogenesis of IBD (Atarashi et al., 2017).

Gut microbes and their polymicrobial invasive biofilms strongly correlated with the incidence of colorectal cancer (CRC) (Dejea et al., 2014). Fusobacterium, a tumorigenic microbe, is enriched in CRC tumor tissue. The fluorescent in situ hybridization (FISH) staining of proximal CRC clinical samples showed that Fusobacterium-containing polymicrobial invasive biofilms existed directly on tumor tissue. Furthermore, clinical samples of tissues containing biofilms had lower levels of E-cadherin and higher expression levels of the inflammatory factor IL-6 and its activator Stat3 than those without biofilms (Dejea et al., 2014). The same group also discovered that biofilm communities on the colon epithelium prepared from CRC patients and even healthy individuals were carcinogenic in murine CRC models (Tomkovich et al., 2019). Moreover, biofilm-forming bacteria from CRC patients interacted with the host and altered host microRNA expression during the development of CRC in murine CRC models (Tomkovich et al., 2020). One species of Fusobacterium, Fusobacterium nucleatum, is frequently detected in liver metastases of Fusobacteriumassociated CRC (Bullman et al., 2017). A treatment with the antibiotic metronidazole reduced the size of tumors in a mouse model of CRC, indicating that $F$. nucleatum is involved in CRC tumor growth (Bullman et al., 2017). F. nucleatum may also induce TLR4 and MYD88 signaling and activate autophagy in CRC, resulting in chemoresistance (Yu et al., 2017). We recently reported that $F$. 
nucleatum elevated the present form of carcinoma to a more advanced stage of CRC, while other bacteria in the early stage of CRC, namely, Atopobium parvulum and Actinomyces odontolyticus, co-occurred in intramucosal carcinomas (Yachida et al., 2019). ETBF and polyketide synthase $(p k s)$ genotoxic island-containing $\left(p k s^{+}\right)$E. coli have also been identified as tumorigenic bacteria (Dejea et al., 2018). The pks genotoxic island encodes the biosynthesis genes of a microbial carcinogen called colibactin, which alkylates DNA and forms colibactin-DNA adducts, resulting in DNA damage and genotoxicity (Wilson et al., 2019). pks $+E$. coli and ETBF co-colonize the colons of patients with familial adenomatous polyposis, which is caused by a hereditary mutation (Dejea et al., 2018). A FISH analysis of clinical samples showed that $p k s+E$. coli and ETBF formed invasive biofilms on the mucosal tissues of FAP patients, and ETBF enhanced pks+ E. coli colonization in the colons of mice (Dejea et al., 2018). Co-colonization in mice increased DNA damage in colonic epithelial cells, colonic tumor formation, and mortality. This tumorigenic effect was attributed to IL-17-induced inflammation (Dejea et al., 2018). Taking these findings from CRC and IBD research into consideration, further studies on the comprehensive spatial information and microbiome compositions of polymicrobial biofilms are important for advancing the development of gut microbiota-targeted treatments.

\section{Gut microbiota and atopic dermatitis/immunology}

Atopic dermatitis (AD) is a skin disease caused by chronic inflammation and is characterized by severe itching, redness, and eczematous skin lesions (Novak et al., 2003). $\mathrm{AD}$ is initiated by the activation of $\mathrm{T}$ helper 2 (Th2) cells and suppression of Th1 (Grewe et al., 1998). Staphylococcus aureus interacts with various cells of the cutaneous immune system to penetrate the epidermis and dermis and perpetuate chronic inflammation (Leyden et al., 1974; Breuer et al., 2002). Alterations in the gut microbiota influence the immune system balance via metabolite production, which may cause an inflamed microenvironment in the specific microbiome of the gut (Zeng et al., 2017; Lee et al., 2018). AD was previously shown to be induced when enteric bacteria from $\mathrm{AD}$ mice were transplanted into healthy sterile mice (Zachariassen et al., 2017). Faecalibacterium, Oscillospira, Bacteroides, Parabacteroides, and Sutterella all have potential as gut microbe biomarkers for AD (Koga et al., 2016; Reddel et al., 2019). The abundance of Clostridium difficile, E. coli, and S. aureus was found to be higher in the gut microbiota of $\mathrm{AD}$ patients than in that of healthy individuals, whereas the amounts of Bifidobacterium and Bacteroides were lower (Kirjavainen et al., 2002; Penders et al., 2006; Abrahamsson et al., 2012; Nylund et al., 2015; Lee et al., 2016). In addition, the SCFA-producing gut microbiota was confirmed to be present in a larger proportion of $\mathrm{AD}$ patients than healthy individuals (Song et al., 2016).

In research on allergies in children who consume yogurt, yogurt consumption correlated with the prevention of $\mathrm{AD}$ (Shoda et al., 2017). Moreover, Faecalibacterium prausnitzii attenuated the symptoms of $\mathrm{AD}$ (Song et al., 2016). Similar findings were observed when Lactobacillus sakei WIKIM30 was orally administered to $\mathrm{BALB} / \mathrm{c}$ mice with induced AD (Kwon et al., 2018). WIKIM30 regulated Th2 and ameliorated AD by increasing the relative abundance of the gut microbiota responsible for the generation of Treg. Lactococcus chungangensis CAU 28, which is in cream cheese, was found to attenuate AD symptoms because it contributed to the suppression of Treg and Th2 immune responses by adjusting SCFAs and the gut microbiota and reducing the number of eosinophils and mast cells as well as immunoglobulin E levels (Kim et al., 2019). In the feces of 11 healthy children and 28 infants who developed $\mathrm{AD}$, the severity of $\mathrm{AD}$ inversely correlated with gut microbiota diversity and butyric acid-producing bacteria (Nylund et al., 2015).

A recent study suggested a relationship between $\mathrm{AD}$ and T helper 17 (Th17) cells (Sugaya, 2020). IL-17 and IL-22 are cytokines that are secreted by Th17 and serve as its marker (Ivanov et al., 2009). A previous study reported that the number of IL-22-producing Th17 cells was significantly increased in the skin of AD patients (Nograles et al., 2009). In another study, the number of IL-17-producing T cells was found to be increased in the peripheral blood and acute lesional skin of $\mathrm{AD}$ patients (Koga et al., 2008). In addition, Treg were shown to attenuate inflammation in $\mathrm{AD}$ mice (Kalekar and Rosenblum, 2019). Although there is currently no information on gut microbial biofilms in the field of $\mathrm{AD}$, the adherence of bacteria and mucosal biofilms may be important for the immunology of $\mathrm{AD}$. For example, segmented filamentous bacterium (SFB) and enterohemorrhagic E. coli (EHEC), which induce the differentiation of Th17, and Clostridia, which induce the differentiation of Treg, are intestinal epithelium-associated or -adhering bacteria (Ivanov et al., 2009; Atarashi et al., 2013; Furusawa et al., 2013; Atarashi et al., 2015). Therefore, researchers need to focus more on the connections between mucosal biofilms and immunology.

\section{Gut microbiota and metabolic disorders}

The prevalence of overweight and obese individuals is a growing epidemic health concern and affected an estimated 1.3 billion individuals worldwide in 2016 (NCD Risk Factor Collaboration, 2017). The progression of certain metabolic disorders, including T2D and atherosclerotic cardiovascular disease (ACVD), is linked to being overweight or obese. Obesity and T2D are both associated with a gut microbiota with an altered composition and function (Qin et al., 2012; Harsch and Konturek, 2018). Although many studies have attempted to elucidate the roles of the gut microbiota in obesity, the precise mechanisms remain unclear because of the complexity of the relationship between the host and microbiota. Diet is one of the environmental factors contributing to obesity, and has been extensively examined in connection with the gut microbiota (Carmody et al., 2015). For example, a Western diet, characterized by high fat and low dietary fiber, has been shown to influence the composition of the gut microbiota and reduce its diversity (He et al., 2018). The findings of a recent study on pre-obese children suggested that the composition of the gut microbiota in conjunction with long-term dietary habits may be helpful for predicting the development of obesity in children (Rampelli et al., 
2018). These findings also indicated that an impaired gut microbiota causes metabolic dysfunction and ultimately obesity in the host (Rampelli et al., 2018). The composition of the gut microbiota of obese animals and humans differs from that of lean subjects (Hartstra et al., 2015; Castaner et al., 2018). The ratio of the phyla Firmicutes and Bacteroidetes was increased in obese subjects and considered to be associated with higher energy absorption from food and elevated low-grade inflammation (Turnbaugh et al., 2006). Additionally, metabolites of the gut microbiota, including SCFAs, LPS, and secondary bile acids, play a critical role in the modulation of metabolism and obesity (Baothman et al., 2016). Increased levels of Enterobacteriaceae and Streptococcus spp. have been identified in the stools of ACVD patients by a metagenome-based study (Jie et al., 2017). Furthermore, the gut bacterial metabolite TMAO produced from choline, l-carnitine, and phosphatidylcholine promoted the progression of ACVD (Wang et al., 2011; Koeth et al., 2013; Tang et al., 2013).

By using culture-based approaches developed in the past decade to examine the gut microbiota (Sommer, 2015), it is possible to investigate the relationship between specific bacterial species and various conditions, including obesity. Endotoxin-producing Enterobacter cloacae has been shown to promote obesity and insulin resistance in germ-free mice (Fei and Zhao, 2013). Similarly, Clostridium ramosum, promoted diet-induced obesity, possibly by enhancing nutrient absorption (Woting et al., 2014). In contrast, some bacterial species exert anti-obesogenic effects (Table 3). For example, supplementation with $A$. muciniphila ameliorated the symptoms of metabolic syndrome induced by a high-fat diet, including fat mass gain, chronic tissue inflammation, metabolic endotoxemia, and insulin resistance, and improved the inflammatory state and gut barrier (Everard et al., 2013). Due to its critical role in the maintenance of metabolic homeostasis, A. muciniphila has been proposed as a nextgeneration probiotic to combat obesity, diabetes, and cardiometabolic disorders (Cani and de Vos, 2017). Prevotella copri performs carbohydrate fermentation from complex polysaccharides in the diet and contributes to better glucose tolerance; therefore, it is regarded as a beneficial bacterium in high-fiber dietary interventions (Kovatcheva-Datchary et al., 2015; De Vadder et al., 2016). Two species of the genus Parabacteroides, Parabacteroides goldsteinii and Parabacteroides distasonis, were found to have the potential to correct obesity-associated abnormalities in mice fed a high-fat diet (Wang et al., 2019a; Wu et al., 2019). These findings on the roles of specific bacterial species in the gut provide important insights for understanding intricate gut microbiota-host interactions. The identification of these proand anti-obesogenic bacteria and a more detailed understanding of the mechanisms underlying this disease will enable us to explore effective approaches for the treatment of metabolic disorders, including obesity. The link between gut microbial biofilms and metabolic disorders currently remains unclear. However, gut microbial biofilms may play a key role because their composition and structure were previously shown to be changed by different diets (Earle et al., 2015).

\section{Gut microbiota and the gut-brain axis}

The gut-brain axis is a system through which the gut microbiota affects brain development, neural activities, and brain disease (Mayer et al., 2014). In recent years, the effects of this relatively unknown system on physical and neurological conditions have been attracting increasing attention.

Many diseases and phenomena have been associated with the gut-brain axis (Schroeder and Bäckhed, 2016; Ye et al., 2018). One example is anxiety-like behavior. Recent studies reported that antibiotics alter the composition of the gut microbiota, which subsequently results in long-term changes in behavior (Burokas et al., 2017; De Palma et al., 2017). Another study showed the attenuation of anxiety-like behavior in the male offspring of pregnant mice exposed to a low dose of penicillin (Leclercq et al., 2017). During defeat sessions in which control group mice and penicillintreated mice were physically subjected to stress by unfamiliar male aggressors, the penicillin-treated group fought back and had fewer scars than control mice, indicating that a deficiency in gut microbes was associated with a reduced fear response (Leclercq et al., 2017). Similarly, an imbalance in the hypothalamic-pituitary-adrenal axis caused by gut microbiome alterations may affect the neuroendocrine system, provoking anxiety-like behavior. After the application of a chronic restraint stress to germ-free and specific pathogen-free mice, specific pathogen-free mice exhibited more anxiety-like behavior than germ-free mice (Huo et al., 2017). In addition, microbiota-derived metabolites were found to contribute to the mental health of the host and relieved psychosocial stress (van de Wouw et al., 2018).

Autism spectrum disorder (ASD) is a severe neurodevelopmental disorder involving impaired social communication and interactions as well as repetitive behavior patterns. The gut microbiota has been suggested to play a critical role in the pathogenesis of ASD. The gut microbiota profiles of ASD patients markedly differ from those of typically developing controls (Kang et al., 2013; Tomova et al., 2015; Liu et al., 2019). Bifidobacterium, Blautia, Dialister, Prevotella, Veillonella, and Turicibacter levels were consistently lower in ASD patients than in healthy controls, whereas Lactobacillus, Bacteroides, Desulfovibrio, and Clostridium levels were higher (Yang et al., 2018; Liu et al., 2019). Similarly, an altered gut microbiota composition was observed in ASD mice (Hsiao et al., 2013; Buffington et al., 2016; Kim et al., 2017a). An altered gut microbiota composition resulted in the production of different metabolites, which may influence the progression of ASD (Wang et al., 2019b). Children with ASD had significantly higher levels of Actinobacteria, but significantly lower species richness than those exhibiting typical development (Wang et al., 2019b). Supplementation with probiotics and fecal microbiota transplantation alleviated the symptoms of ASD in children (Steenbergen et al., 2015; Kang et al., 2017). Interestingly, specific bacterial species, such as $B$. fragilis and Lactobacillus reuteri, have therapeutic potential in animal models of ASD (Hsiao et al., 2013; Buffington et al., 2016).

The effects of gut microbial communities on physical and neurological conditions have also been examined in Alz- 
Table 3. Roles of specific bacterial species with anti-obesogenic effects

\begin{tabular}{|c|c|c|c|c|}
\hline Bacterium & Subject & $\begin{array}{l}\text { Treatment } \\
\text { period }\end{array}$ & Outcomes & Reference \\
\hline $\begin{array}{l}\text { Akkermansia } \\
\text { muciniphila }\end{array}$ & Mice & 4 weeks & $\begin{array}{l}\text { Alleviates high-fat diet-induced metabolic symptoms, including } \\
\text { endotoxemia, fat mass gain, adipose tissue inflammation, and } \\
\text { insulin resistance; improves inflammation, gut barrier function, and } \\
\text { gut peptide secretion }\end{array}$ & Everard et al., 2013 \\
\hline Prevotella copri & Mice & 2 weeks & $\begin{array}{l}\text { Performs carbohydrate fermentation from complex polysaccharides } \\
\text { in the diet and contributes to better glucose tolerance }\end{array}$ & $\begin{array}{l}\text { Kovatcheva-Datchary } \\
\text { et al., } 2015\end{array}$ \\
\hline $\begin{array}{l}\text { Bifidobacterium breve } \\
\text { B-3 }\end{array}$ & Mice & 8 weeks & $\begin{array}{l}\text { Reduces the accumulation of body weight and epididymal fat and } \\
\text { alleviates serum levels of fasting glucose, cholesterol, and insulin }\end{array}$ & Kondo et al., 2010 \\
\hline $\begin{array}{l}\text { Bifidobacterium breve } \\
\text { B-3 }\end{array}$ & $\begin{array}{l}\text { Pre-obesity } \\
\quad \text { adults }\end{array}$ & 12 weeks & $\begin{array}{l}\text { Reduces fat mass and alleviates parameters associated with liver } \\
\text { functions and inflammation, including } \gamma \text {-glutamyltranspeptidase } \\
\text { and high-sensitivity C-reactive protein }\end{array}$ & Minami et al., 2015 \\
\hline $\begin{array}{l}\text { Bifidobacterium } \\
\text { pseudocatenulatum }\end{array}$ & Mice & 8 weeks & $\begin{array}{l}\text { Reduces body weight and fat mass, fasting glucose, and insulin } \\
\text { resistance }\end{array}$ & Zhao et al., 2018 \\
\hline Lactobacillus gasseri & $\begin{array}{l}\text { Healthy } \\
\text { adults with } \\
\text { large } \\
\text { visceral fat } \\
\text { areas }\end{array}$ & 12 weeks & $\begin{array}{l}\text { Reduces abdominal visceral fat areas, the body mass index, hip and } \\
\text { waist circumferences, and body fat }\end{array}$ & Kadooka et al., 2013 \\
\hline Bacteroides uniformis & Mice & 7 weeks & $\begin{array}{l}\text { Suppresses body weight gain; improves liver function by reducing } \\
\text { liver steatosis as well as liver cholesterol and triglycerides; reduces } \\
\text { dietary fat absorption and reverses immune dysfunction }\end{array}$ & $\begin{array}{l}\text { Gauffin Cano et al., } \\
2012\end{array}$ \\
\hline Bacteroides acidifaciens & Mice & 10 weeks & $\begin{array}{l}\text { Suppresses body weight and fat mass; ameliorates insulin } \\
\text { resistance; increases serum GLP-1 and decreases gut dipeptidyl } \\
\text { peptidase- } 4\end{array}$ & Yang et al., 2017b \\
\hline $\begin{array}{l}\text { Bacteroides } \\
\text { thetaiotaomicron }\end{array}$ & Mice & 7 weeks & $\begin{array}{l}\text { In chow diet-fed mice, reduces fat mass and increases lean body } \\
\text { mass; in high-fat diet-fed mice, suppresses body weight gain and } \\
\text { adiposity, increases serum adiponectin and decreases leptin, up- } \\
\text { regulates the expression of genes for fatty acid oxidation and } \\
\text { lipolysis, and improves the inflammatory status }\end{array}$ & Liu et al., 2017 \\
\hline Eubacterium hallii & $d b / d b$ mice & 5 weeks & $\begin{array}{l}\text { Decreases insulin sensitivity and increases energy expenditure and } \\
\text { fecal butyrate concentrations }\end{array}$ & $\begin{array}{l}\text { Udayappan et al., } \\
2016\end{array}$ \\
\hline $\begin{array}{l}\text { Parabacteroides } \\
\text { goldsteinii }\end{array}$ & Mice & 8 weeks & $\begin{array}{l}\text { Ameliorates obesity and increases adipose tissue thermogenesis; } \\
\text { enhances gut integrity; lowers the inflammatory status; increases } \\
\text { insulin sensitivity }\end{array}$ & Wu et al., 2019 \\
\hline $\begin{array}{l}\text { Parabacteroides } \\
\text { distasonis }\end{array}$ & Mice & 5 weeks & $\begin{array}{l}\text { Reduces weight gain, hyperglycemia, and hepatic steatosis; alters } \\
\text { the bile acid profile; increases gut gluconeogenesis and insulin } \\
\text { sensitivity }\end{array}$ & Wang et al., 2019a \\
\hline
\end{tabular}

heimer's disease (AZD). Accounting for $\sim 70 \%$ of all dementia cases, AZD is the most common form of dementia (Ko et al., 2019). The diversity of the gut microbiota was previously reported to be lower in AZD patients than in ageand sex-matched control individuals (Vogt et al., 2017). Bile acids also play an important role in the development of AZD. A recent study compared the bile acid profiles of healthy adults, adults with early mild cognitive impairment, adults with late mild cognitive impairment, and AZD patients, and found that primary bile acid levels were lower and microbiota-produced secondary bile acid levels were higher in subjects with cognitive impairment (MahmoudianDehkordi et al., 2019). Therefore, specific changes in the gut microbial community were suggested to alter the levels of secondary bile acids, conceivably contributing to the pathogenesis of AZD (MahmoudianDehkordi et al., 2019).

Similar gut microbiota alterations have been observed in Parkinson's disease (PD) patients (Scheperjans et al., 2015; Hill-Burns et al., 2017). The symptoms of PD, a progressive nervous system disorder, include motor deficits, such as tremors, rigid muscles, and bradykinesia (Nalls et al., 2014). In PD patients, gut bacteria from the family Prevotellaceae were $77.6 \%$ lower than in healthy individuals (Scheperjans et al., 2015). Another study transplanted the gut microbiota from PD patients to germ-free mice, and detected physical impairments due to neurodegeneration in recipient mice
(Sampson et al., 2016). Collectively, these findings indicate that gut microbes contribute to the progression of PD.

Gut-innervating nociceptor neurons have been shown to inhibit Salmonella infection through the modulation of Peyer's Patch microfold cells and gut adherence bacterium SFB levels (Lai et al., 2020). Although the relationships between bacterial adherence or biofilm formation and the brain currently remain unclear, some relationships appear to exist between the adherence of gut microbes and the neurological system.

\section{Conclusions}

Various omics technologies enable us to obtain extensive information in a high-throughput manner in gut microbe research. The development of the integrated omics analysis method, metabologenomics, has facilitated research on complex gut microbiota communities and gut microbiota-host interaction networks (Ishii et al., 2018). Large cohort studies and high-throughput omics techniques may be commonly used in this area of study. However, difficulties may be associated with investigating host-microbiota interactions by solely relying on an omics analysis. As shown in studies on IBD and CRC, spatial information on the intestinal mucosal surface is important for examining host-microbiota interactions. Therefore, gut microbiota research may need to shift its focus from the compositional traits and variations of 


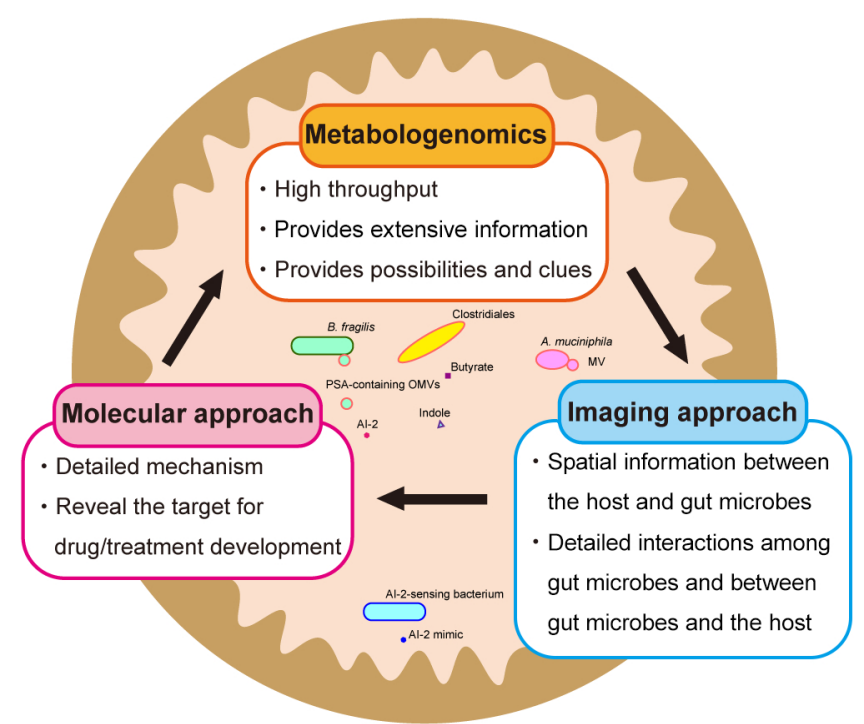

Fig. 3. A synergistic approach integrating metabologenomics, imaging, and molecular technologies. The integrated omics analysis method, metabologenomics provides us with extensive information on the relationships between microbiota, metabolites, and the host with many possibilities and clues for further research (Ishii et al., 2018). The imaging approach enables us to gain spatial information between the host and gut microbes, and a more detailed understanding of the interactions among gut microbes as well as gut microbes with the host. The molecular approach reveals detailed mechanisms and targets for the drug/treatment development. Novel synergy between metabologenomics, imaging approaches, and molecular approaches will allow us to elucidate the mechanisms underlying gut microbe-host interactions and host immune defenses on the intestinal mucosal barrier in order to develop better solutions for human health issues.

gut microbiota and metabolites to integrating them into the spatial and temporal dynamics of gut microbial biofilms. Therefore, it is important to incorporate spatio-temporal characterizations using microscopic imaging and molecular biology analyses because they may contribute to clarifying the detailed mechanisms underlying gut microbiota-host interactions and host immune defenses on the intestinal mucosal barrier and also reveal new targets for drug/treatment development (Fig. 3) (Swidsinski et al., 2005; Dejea et al., 2014; Atarashi et al., 2017; Bullman et al., 2017; Yu et al., 2017; Dejea et al., 2018; Wilson et al., 2019). Novel synergy among these approaches will revolutionize the field of gut microbiology, thereby allowing us to make more contributions toward maintaining and promoting optimal host health for a higher quality of life.

\section{Acknowledgements}

We thank Drs. Justin L. Sonnenburg, Kerwyn Casey Huang, Katherine Ng, Carolina Tropini, Kali Pruss, Kim Vasquez, Toshifumi Osaka, and Satoshi Tsuneda for their technical assistance. This work was supported in part by JSPS KAKENHI (18H04805 to S.F.), JST PRESTO (JPMJPR1537 to S.F.), AMED-CREST (JP19gm1010009 to S.F.), JST ERATO (JPMJER1502 to N.N., JPMJER1902 to S.F.), the Takeda Science Foundation (to S.F.), the Food Science Institute Foundation (to S.F.), the Program for the Advancement of Research in Core Projects under Keio University's Longevity Initiative (to S.F.), and the Yamagata Prefectural Government and the City of Tsuruoka (to M.T.).

\section{References}

Abrahamsson, T.R., Jakobsson, H.E., Andersson, A.F., Björkstén, B., Engstrand, L., and Jenmalm, M.C. (2012) Low diversity of the gut microbiota in infants with atopic eczema. $J$ Allergy Clin Immunol 129: 434-440, 440.e431-432.

Arumugam, M., Raes, J., Pelletier, E., Le Paslier, D., Yamada, T., Mende, D.R., et al. (2011) Enterotypes of the human gut microbiome. Nature 473: $174-180$.

Atarashi, K., Tanoue, T., Oshima, K., Suda, W., Nagano, Y., Nishikawa, H., et al. (2013) Treg induction by a rationally selected mixture of Clostridia strains from the human microbiota. Nature 500: 232-236.

Atarashi, K., Tanoue, T., Ando, M., Kamada, N., Nagano, Y., Narushima, S., et al. (2015) Th17 cell induction by adhesion of microbes to intestinal epithelial cells. Cell 163: 367-380.

Atarashi, K., Suda, W., Luo, C., Kawaguchi, T., Motoo, I., Narushima, S., et al. (2017) Ectopic colonization of oral bacteria in the intestine drives T. Science 358: 359-365.

Bansal, T., Alaniz, R.C., Wood, T.K., and Jayaraman, A. (2010) The bacterial signal indole increases epithelial-cell tight-junction resistance and attenuates indicators of inflammation. Proc Natl Acad Sci U S A 107: 228-233.

Baothman, O.A., Zamzami, M.A., Taher, I., Abubaker, J., and AbuFarha, M. (2016) The role of gut microbiota in the development of obesity and diabetes. Lipids Health Dis 15: 108.

Belenguer, A., Duncan, S.H., Calder, A.G., Holtrop, G., Louis, P., Lobley, G.E., and Flint, H.J. (2006) Two routes of metabolic crossfeeding between Bifidobacterium adolescentis and butyrateproducing anaerobes from the human gut. Appl Environ Microbiol 72: 3593-3599.

Breuer, K., HAussler, S., Kapp, A., and Werfel, T. (2002) Staphylococcus aureus: colonizing features and influence of an antibacterial treatment in adults with atopic dermatitis. Br J Dermatol 147: 55-61.

Brown, A.J., Goldsworthy, S.M., Barnes, A.A., Eilert, M.M., Tcheang, L., Daniels, D., et al. (2003) The Orphan G protein-coupled receptors GPR41 and GPR43 are activated by propionate and other short chain carboxylic acids. J Biol Chem 278: 11312-11319.

Buffington, S.A., Di Prisco, G.V., Auchtung, T.A., Ajami, N.J., Petrosino, J.F., and Costa-Mattioli, M. (2016) Microbial reconstitution reverses maternal diet-induced social and synaptic deficits in offspring. Cell 165: 1762-1775.

Bullman, S., Pedamallu, C.S., Sicinska, E., Clancy, T.E., Zhang, X., Cai, D., et al. (2017) Analysis of Fusobacterium persistence and antibiotic response in colorectal cancer. Science 358: 1443-1448.

Bunesova, V., Lacroix, C., and Schwab, C. (2018) Mucin cross-feeding of infant Bifidobacteria and Eubacterium hallii. Microb Ecol 75: 228-238.

Burokas, A., Arboleya, S., Moloney, R.D., Peterson, V.L., Murphy, K., Clarke, G., et al. (2017) Targeting the microbiota-gut-brain axis: Prebiotics have anxiolytic and antidepressant-like effects and reverse the impact of chronic stress in mice. Biol Psychiatry 82: 472-487.

Byndloss, M.X., Olsan, E.E., Rivera-Chávez, F., Tiffany, C.R., Cevallos, S.A., Lokken, K.L., et al. (2017) Microbiota-activated PPAR- $\gamma$ signaling inhibits dysbiotic Enterobacteriaceae expansion. Science 357: $570-575$.

Canas, M.A., Fabrega, M.J., Gimenez, R., Badia, J., and Baldoma, L. (2018) Outer membrane vesicles from probiotic and commensal Escherichia coli activate NOD1-mediated immune responses in intestinal epithelial cells. Front Microbiol 9: 498.

Cani, P.D., and de Vos, W.M. (2017) Next-generation beneficial microbes: The case of Akkermansia muciniphila. Front Microbiol 8: 1765 .

Cani, P.D. (2018) Human gut microbiome: hopes, threats and promises. Gut 67: 1716-1725.

Carmody, R.N., Gerber, G.K., Luevano, J.M., Gatti, D.M., Somes, L., Svenson, K.L., and Turnbaugh, P.J. (2015) Diet dominates host genotype in shaping the murine gut microbiota. Cell Host Microbe 17: $72-84$.

Castaner, O., Goday, A., Park, Y.M., Lee, S.H., Magkos, F., Shiow, S.T.E., and Schröder, H. (2018) The Gut microbiome profile in obesity: A systematic review. Int J Endocrinol 2018: 4095789. 
Chelakkot, C., Choi, Y., Kim, D.K., Park, H.T., Ghim, J., Kwon, Y., et al. (2018) Akkermansia muciniphila-derived extracellular vesicles influence gut permeability through the regulation of tight junctions. Exp Mol Med 50: e450.

Chimerel, C., Emery, E., Summers, D.K., Keyser, U., Gribble, F.M., and Reimann, F. (2014) Bacterial metabolite indole modulates incretin secretion from intestinal enteroendocrine L cells. Cell Rep 9: 12021208.

Đapa, T., Leuzzi, R., Ng, Y.K., Baban, S.T., Adamo, R., Kuehne, S.A., et al. (2013) Multiple factors modulate biofilm formation by the anaerobic pathogen Clostridium difficile. J Bacteriol 195: 545-555.

De Palma, G., Lynch, M.D., Lu, J., Dang, V.T., Deng, Y., Jury, J., et al. (2017) Transplantation of fecal microbiota from patients with irritable bowel syndrome alters gut function and behavior in recipient mice. Sci Transl Med 9: eaaf6397.

De Vadder, F., Kovatcheva-Datchary, P., Zitoun, C., Duchampt, A., Bäckhed, F., and Mithieux, G. (2016) Microbiota-produced succinate improves glucose homeostasis via intestinal gluconeogenesis. Cell Metab 24: 151-157.

Dejea, C.M., Wick, E.C., Hechenbleikner, E.M., White, J.R., Mark Welch, J.L., Rossetti, B.J., et al. (2014) Microbiota organization is a distinct feature of proximal colorectal cancers. Proc Natl Acad Sci U S A 111: 18321-18326.

Dejea, C.M., Fathi, P., Craig, J.M., Boleij, A., Taddese, R., Geis, A.L., et al. (2018) Patients with familial adenomatous polyposis harbor colonic biofilms containing tumorigenic bacteria. Science 359: 592597.

Desai, M.S., Seekatz, A.M., Koropatkin, N.M., Kamada, N., Hickey, C.A., Wolter, M., et al. (2016) A dietary fiber-deprived gut microbiota degrades the colonic mucus barrier and enhances pathogen susceptibility. Cell 167: 1339-1353.e1321.

Dobell, C. (1932) Anthony van Leeuwenhoek and His "Little Animals". London: Staples Press.

Earle, K.A., Billings, G., Sigal, M., Lichtman, J.S., Hansson, G.C., Elias, J.E., et al. (2015) Quantitative imaging of gut microbiota spatial organization. Cell Host Microbe 18: 478-488.

Escherich, T. (1885) Die Darmbakterien des Neugeborenen und Sauglings. Fortschr Med 3: 515-522.

Everard, A., Belzer, C., Geurts, L., Ouwerkerk, J.P., Druart, C., Bindels, L.B., et al. (2013) Cross-talk between Akkermansia muciniphila and intestinal epithelium controls diet-induced obesity. Proc Natl Acad Sci U S A 110: 9066-9071.

Fei, N., and Zhao, L. (2013) An opportunistic pathogen isolated from the gut of an obese human causes obesity in germfree mice. ISME $J$ 7: $880-884$.

Flemming, H.C., Wingender, J., Szewzyk, U., Steinberg, P., Rice, S.A., and Kjelleberg, S. (2016) Biofilms: an emergent form of bacterial life. Nat Rev Microbiol 14: 563-575.

Fukuda, S., Toh, H., Hase, K., Oshima, K., Nakanishi, Y., Yoshimura, K., et al. (2011) Bifidobacteria can protect from enteropathogenic infection through production of acetate. Nature 469: 543-547.

Fukuda, S., and Ohno, H. (2014) Gut microbiome and metabolic diseases. Semin Immunopathol 36: 103-114.

Fukuda, S. (2019) For the Better Understanding: Gut Microbiota. Tokyo: Yodosha (in Japanese)

Furusawa, Y., Obata, Y., Fukuda, S., Endo, T.A., Nakato, G., Takahashi, D., et al. (2013) Commensal microbe-derived butyrate induces the differentiation of colonic regulatory T cells. Nature 504: 446-450.

Gauffin Cano, P., Santacruz, A., Moya, Á., and Sanz, Y. (2012) Bacteroides uniformis CECT 7771 ameliorates metabolic and immunological dysfunction in mice with high-fat-diet induced obesity. PLoS One 7: e41079.

González Barrios, A.F., Zuo, R., Hashimoto, Y., Yang, L., Bentley, W.E., and Wood, T.K. (2006) Autoinducer 2 controls biofilm formation in Escherichia coli through a novel motility quorum-sensing regulator (MqsR, B3022). J Bacteriol 188: 305-316.

Grewe, M., Bruijnzeel-Koomen, C.A., Schöpf, E., Thepen, T., Langeveld-Wildschut, A.G., Ruzicka, T., and Krutmann, J. (1998) A role for Th1 and Th2 cells in the immunopathogenesis of atopic dermatitis. Immunol Today 19: 359-361.

Harsch, I.A., and Konturek, P.C. (2018) The role of gut microbiota in obesity and type 2 and type 1 diabetes mellitus: New insights into "old" diseases. Med Sci 6: 32.
Hartstra, A.V., Bouter, K.E., Bäckhed, F., and Nieuwdorp, M. (2015) Insights into the role of the microbiome in obesity and type 2 diabetes. Diabetes Care 38: 159-165.

He, C., Cheng, D., Peng, C., Li, Y., Zhu, Y., and Lu, N. (2018) High-fat diet induces dysbiosis of gastric microbiota prior to gut microbiota in association with metabolic disorders in mice. Front Microbiol 9: 639.

Hill-Burns, E.M., Debelius, J.W., Morton, J.T., Wissemann, W.T., Lewis, M.R., Wallen, Z.D., et al. (2017) Parkinson's disease and Parkinson's disease medications have distinct signatures of the gut microbiome. Mov Disord 32: 739-749.

Hooper, L.V., and Gordon, J.I. (2001) Commensal host-bacterial relationships in the gut. Science 292: 1115-1118.

Hsiao, A., Ahmed, A.M., Subramanian, S., Griffin, N.W., Drewry, L.L., Petri, W.A., et al. (2014) Members of the human gut microbiota involved in recovery from Vibrio cholerae infection. Nature 515: 423-426.

Hsiao, E.Y., McBride, S.W., Hsien, S., Sharon, G., Hyde, E.R., McCue, T., et al. (2013) Microbiota modulate behavioral and physiological abnormalities associated with neurodevelopmental disorders. Cell 155: $1451-1463$.

Human Microbiome Project Consortium (2012) Structure, function and diversity of the healthy human microbiome. Nature 486: 207-214.

Huo, R., Zeng, B., Zeng, L., Cheng, K., Li, B., Luo, Y., et al. (2017) Microbiota modulate anxiety-like behavior and endocrine abnormalities in hypothalamic-pituitary-adrenal axis. Front Cell Infect Microbiol 7: 489.

International Human Genome Sequencing Consortium (2004) Finishing the euchromatic sequence of the human genome. Nature 431: 931945.

Ishii, C., Nakanishi, Y., Murakami, S., Nozu, R., Ueno, M., Hioki, K., et al. (2018) A metabologenomic approach reveals changes in the intestinal environment of mice fed on American diet. Int $J$ Mol Sci 19: 4079.

Ishii, N., Nakahigashi, K., Baba, T., Robert, M., Soga, T., Kanai, A., et al. (2007) Multiple high-throughput analyses monitor the response of E. coli to perturbations. Science 316: 593-597.

Ismail, A.S., Valastyan, J.S., and Bassler, B.L. (2016) A host-produced autoinducer-2 mimic activates bacterial quorum sensing. Cell Host Microbe 19: 470-480.

Ivanov, I.I., Atarashi, K., Manel, N., Brodie, E.L., Shima, T., Karaoz, U., et al. (2009) Induction of intestinal Th17 cells by segmented filamentous bacteria. Cell 139: 485-498.

Jaglin, M., Rhimi, M., Philippe, C., Pons, N., Bruneau, A., Goustard, B., et al. (2018) Indole, a signaling molecule produced by the gut microbiota, negatively impacts emotional behaviors in rats. Front Neurosci 12: 216.

Jia, W., Xie, G., and Jia, W. (2018) Bile acid-microbiota crosstalk in gastrointestinal inflammation and carcinogenesis. Nat Rev Gastroenterol Hepatol 15: 111-128.

Jie, Z., Xia, H., Zhong, S.L., Feng, Q., Li, S., Liang, S., et al. (2017) The gut microbiome in atherosclerotic cardiovascular disease. Nat Commun 8: 845

Johansson, M.E., Gustafsson, J.K., Holmén-Larsson, J., Jabbar, K.S., Xia, L., Xu, H., et al. (2014) Bacteria penetrate the normally impenetrable inner colon mucus layer in both murine colitis models and patients with ulcerative colitis. Gut 63: 281-291.

Kadooka, Y., Sato, M., Ogawa, A., Miyoshi, M., Uenishi, H., Ogawa, H., et al. (2013) Effect of Lactobacillus gasseri SBT2055 in fermented milk on abdominal adiposity in adults in a randomised controlled trial. Br J Nutr 110: 1696-1703.

Kalekar, L.A., and Rosenblum, M.D. (2019) Regulatory T cells in inflammatory skin disease: from mice to humans. Int Immunol 31: 457-463.

Kang, D.W., Park, J.G., Ilhan, Z.E., Wallstrom, G., Labaer, J., Adams, J.B., and Krajmalnik-Brown, R. (2013) Reduced incidence of Prevotella and other fermenters in intestinal microflora of autistic children. PLoS One 8: e68322.

Kang, D.W., Adams, J.B., Gregory, A.C., Borody, T., Chittick, L., Fasano, A., et al. (2017) Microbiota transfer therapy alters gut ecosystem and improves gastrointestinal and autism symptoms: an open-label study. Microbiome 5: 10.

Kim, J.H., Kim, K., and Kim, W. (2019) Cream cheese-derived Lactococcus chungangensis CAU 28 modulates the gut microbiota and alleviates atopic dermatitis in BALB/c Mice. Sci Rep 9: 446. 
Kim, S., Kim, H., Yim, Y.S., Ha, S., Atarashi, K., Tan, T.G., et al. (2017a) Maternal gut bacteria promote neurodevelopmental abnormalities in mouse offspring. Nature 549: 528-532.

Kim, Y.G., Sakamoto, K., Seo, S.U., Pickard, J.M., Gillilland, M.G., Pudlo, N.A., et al. (2017b) Neonatal acquisition of Clostridia species protects against colonization by bacterial pathogens. Science 356: 315-319.

Kirjavainen, P.V., Arvola, T., Salminen, S.J., and Isolauri, E. (2002) Aberrant composition of gut microbiota of allergic infants: a target of bifidobacterial therapy at weaning? Gut 51: 51-55.

Knights, D., Ward, T.L., McKinlay, C.E., Miller, H., Gonzalez, A., McDonald, D., and Knight, R. (2014) Rethinking “enterotypes”. Cell Host Microbe 16: 433-437.

Ko, H., Ihm, J.J., Kim, H.G., and Initiative, A.s.D.N. (2019) Cognitive profiling related to cerebral amyloid beta burden using machine learning approaches. Front Aging Neurosci 11: 95.

Koeth, R.A., Wang, Z., Levison, B.S., Buffa, J.A., Org, E., Sheehy, B.T., et al. (2013) Intestinal microbiota metabolism of L-carnitine, a nutrient in red meat, promotes atherosclerosis. Nat Med 19: 576585.

Koga, C., Kabashima, K., Shiraishi, N., Kobayashi, M., and Tokura, Y. (2008) Possible pathogenic role of Th17 cells for atopic dermatitis. $J$ Invest Dermatol 128: 2625-2630.

Koga, Y., Tokunaga, S., Nagano, J., Sato, F., Konishi, K., Tochio, T., et al. (2016) Age-associated effect of kestose on Faecalibacterium prausnitzii and symptoms in the atopic dermatitis infants. Pediatr Res 80: 844-851.

Kondo, S., Xiao, J.Z., Satoh, T., Odamaki, T., Takahashi, S., Sugahara, H., et al. (2010) Antiobesity effects of Bifidobacterium breve strain B-3 supplementation in a mouse model with high-fat diet-induced obesity. Biosci Biotechnol Biochem 74: 1656-1661.

Kovatcheva-Datchary, P., Nilsson, A., Akrami, R., Lee, Y.S., De Vadder, F., Arora, T., et al. (2015) Dietary fiber-induced improvement in glucose metabolism is associated with increased abundance of prevotella. Cell Metab 22: 971-982.

Kurokawa, K., Itoh, T., Kuwahara, T., Oshima, K., Toh, H., Toyoda, A., et al. (2007) Comparative metagenomics revealed commonly enriched gene sets in human gut microbiomes. DNA Res 14: 169181.

Kwon, M.S., Lim, S.K., Jang, J.Y., Lee, J., Park, H.K., Kim, N., et al. (2018) Lactobacillus sakei WIKIM30 ameliorates atopic dermatitislike skin lesions by inducing regulatory $\mathrm{T}$ cells and altering gut microbiota structure in nice. Front Immunol 9: 1905.

Laganenka, L., and Sourjik, V. (2018) Autoinducer 2-dependent Escherichia coli biofilm formation is enhanced in a dual-species coculture. Appl Environ Microbiol 84: e2638-17.

Lai, N.Y., Musser, M.A., Pinho-Ribeiro, F.A., Baral, P., Jacobson, A., Ma, P., et al. (2020) Gut-innervating nociceptor neurons regulate Peyer's patch microfold cells and SFB levels to mediate Salmonella host defense. Cell 180: 33-49.e22.

Leclercq, S., Mian, F.M., Stanisz, A.M., Bindels, L.B., Cambier, E., BenAmram, H., et al. (2017) Low-dose penicillin in early life induces long-term changes in murine gut microbiota, brain cytokines and behavior. Nat Commun 8: 15062 .

Lee, E., Lee, S.Y., Kang, M.J., Kim, K., Won, S., Kim, B.J., et al. (2016) Clostridia in the gut and onset of atopic dermatitis via eosinophilic inflammation. Ann Allergy, Asthma, Immunol 117: 91-92.e91.

Lee, S.Y., Lee, E., Park, Y.M., and Hong, S.J. (2018) Microbiome in the gut-skin axis in atopic dermatitis. Allergy, Asthma Immunol Res 10: 354-362.

Leidy, J. (1849) On the existence of entophyta in healthy animals, as a natural condition. Proc Acad Nat Sci Philadelphia 4: 225-233.

Levy, M., Kolodziejczyk, A.A., Thaiss, C.A., and Elinav, E. (2017) Dysbiosis and the immune system. Nat Rev Immunol 17: 219-232.

Leyden, J.J., Marples, R.R., and Kligman, A.M. (1974) Staphylococcus aureus in the lesions of atopic dermatitis. Br J Dermatol 90: 525530.

Liu, F., Li, J., Wu, F., Zheng, H., Peng, Q., and Zhou, H. (2019) Altered composition and function of intestinal microbiota in autism spectrum disorders: a systematic review. Transl Psychiatry 9: 43.

Liu, R., Hong, J., Xu, X., Feng, Q., Zhang, D., Gu, Y., et al. (2017) Gut microbiome and serum metabolome alterations in obesity and after weight-loss intervention. Nat Med 23: 859-868.

Macfarlane, S., and Dillon, J.F. (2007) Microbial biofilms in the human gastrointestinal tract. J Appl Microbiol 102: 1187-1196.
MahmoudianDehkordi, S., Arnold, M., Nho, K., Ahmad, S., Jia, W., Xie, G.X., et al. (2019) Altered bile acid profile associates with cognitive impairment in Alzheimer's disease-An emerging role for gut microbiome. Alzheimer's Dementia 15: 76-92.

Mayer, E.A., Padua, D., and Tillisch, K. (2014) Altered brain-gut axis in autism: comorbidity or causative mechanisms? BioEssays 36: 933 939.

Minami, J., Kondo, S., Yanagisawa, N., Odamaki, T., Xiao, J.Z., Abe, F., et al. (2015) Oral administration of Bifidobacterium breve B-3 modifies metabolic functions in adults with obese tendencies in a randomised controlled trial. J Nutr Sci 4: e17.

Mitsuoka, T., Morishita, Y., Terada, A., and Yamamoto, S. (1969) A simple method ("plate-in-bottle method") for the cultivation of fastidious anaerobes. Jpn J Microbiol 13: 383-385.

Moro, E. (1900) Über den Bacillus acidophilus n. sp. Jahrb Kinderheilk 52: $38-55$.

Mukherjee, S., and Bassler, B.L. (2019) Bacterial quorum sensing in complex and dynamically changing environments. Nat Rev Microbiol 17: 371-382.

Mullis, K.B., and Faloona, F.A. (1987) Specific synthesis of DNA in vitro via a polymerase-catalyzed chain reaction. Methods Enzymol 155: 335-350.

Nagao-Kitamoto, H., and Kamada, N. (2017) Host-microbial cross-talk in inflammatory bowel disease. Immune Netw 17: 1-12.

Nalls, M.A., Pankratz, N., Lill, C.M., Do, C.B., Hernandez, D.G., Saad, M., et al. (2014) Large-scale meta-analysis of genome-wide association data identifies six new risk loci for Parkinson's disease. Nat Genet 46: 989-993.

NCD Risk Factor Collaboration (2017) Worldwide trends in body-mass index, underweight, overweight, and obesity from 1975 to 2016: a pooled analysis of 2416 population-based measurement studies in 128.9 million children, adolescents, and adults. Lancet 390: 2627 2642

Netea, M.G., Joosten, L.A., Latz, E., Mills, K.H., Natoli, G., Stunnenberg, H.G., et al. (2016) Trained immunity: A program of innate immune memory in health and disease. Science 352: aaf1098.

Nograles, K.E., Zaba, L.C., Shemer, A., Fuentes-Duculan, J., Cardinale, I., Kikuchi, T., et al. (2009) IL-22-producing “T22" T cells account for upregulated IL-22 in atopic dermatitis despite reduced IL-17producing TH17 T cells. J Allergy Clin Immunol 123: 1244 1252.e1242.

Novak, N., Bieber, T., and Leung, D.Y. (2003) Immune mechanisms leading to atopic dermatitis. J Allergy Clin Immunol 112: S128-139.

Nylund, L., Nermes, M., Isolauri, E., Salminen, S., de Vos, W.M., and Satokari, R. (2015) Severity of atopic disease inversely correlates with intestinal microbiota diversity and butyrate-producing bacteria. Allergy (Oxford, U K) 70: 241-244.

Obana, N., Nakao, R., Nagayama, K., Nakamura, K., Senpuku, H., and Nomura, N. (2017) Immunoactive clostridial membrane vesicle production is regulated by a sporulation factor. Infect Immun $\mathbf{8 5}$ e00096-17.

Okada, T., Fukuda, S., Hase, K., Nishiumi, S., Izumi, Y., Yoshida, M., et al. (2013) Microbiota-derived lactate accelerates colon epithelial cell turnover in starvation-refed mice. Nat Commun 4: 1654.

Pareek, S., Kurakawa, T., Das, B., Motooka, D., Nakaya, S., RongsenChandola, T., et al. (2019) Comparison of Japanese and Indian intestinal microbiota shows diet-dependent interaction between bacteria and fungi. NPJ Biofilms Microbiomes 5: 37.

Penders, J., Stobberingh, E.E., Thijs, C., Adams, H., Vink, C., van Ree, R., and van den Brandt, P.A. (2006) Molecular fingerprinting of the intestinal microbiota of infants in whom atopic eczema was or was not developing. Clin Exp Allergy 36: 1602-1608.

Qin, J., Li, Y., Cai, Z., Li, S., Zhu, J., Zhang, F., et al. (2012) A metagenome-wide association study of gut microbiota in type 2 diabetes. Nature 490: 55-60.

Quintin, J., Saeed, S., Martens, J.H.A., Giamarellos-Bourboulis, E.J., Ifrim, D.C., Logie, C., et al. (2012) Candida albicans infection affords protection against reinfection via functional reprogramming of monocytes. Cell Host Microbe 12: 223-232.

Rampelli, S., Guenther, K., Turroni, S., Wolters, M., Veidebaum, T., Kourides, Y., et al. (2018) Pre-obese children's dysbiotic gut microbiome and unhealthy diets may predict the development of obesity. Commun Biol 1: 222. 
Reddel, S., Del Chierico, F., Quagliariello, A., Giancristoforo, S., Vernocchi, P., Russo, A., et al. (2019) Gut microbiota profile in children affected by atopic dermatitis and evaluation of intestinal persistence of a probiotic mixture. Sci Rep 9: 4996.

Saeed, S., Quintin, J., Kerstens, H.H., Rao, N.A., Aghajanirefah, A., Matarese, F., et al. (2014) Epigenetic programming of monocyte-tomacrophage differentiation and trained innate immunity. Science 345: 1251086 .

Sakanaka, A., Kuboniwa, M., Takeuchi, H., Hashino, E., and Amano, A. (2015) Arginine-ornithine antiporter ArcD controls arginine metabolism and interspecies biofilm development of Streptococcus gordonii. J Biol Chem 290: 21185-21198.

Sampson, T.R., Debelius, J.W., Thron, T., Janssen, S., Shastri, G.G., Ilhan, Z.E., et al. (2016) Gut microbiota regulate motor deficits and neuroinflammation in a model of Parkinson's disease. Cell 167: 1469-1480.e1412.

Sanger, F., and Coulson, A.R. (1975) A rapid method for determining sequences in DNA by primed synthesis with DNA polymerase. $J$ Mol Biol 94: 441-448.

Scheperjans, F., Aho, V., Pereira, P.A.B., Koskinen, K., Paulin, L., Pekkonen, E., et al. (2015) Gut microbiota are related to Parkinson's disease and clinical phenotype. Mov Disord 30: 350-358.

Schroeder, B.O., and Bäckhed, F. (2016) Signals from the gut microbiota to distant organs in physiology and disease. Nat Med 22: 1079-1089.

Sender, R., Fuchs, S., and Milo, R. (2016) Revised estimates for the number of human and bacteria cells in the body. PLoS Biol 14: e1002533.

Shen, Y., Giardino Torchia, M.L., Lawson, G.W., Karp, C.L., Ashwell, J.D., and Mazmanian, S.K. (2012) Outer membrane vesicles of a human commensal mediate immune regulation and disease protection. Cell Host Microbe 12: 509-520.

Shoda, T., Futamura, M., Yang, L., Narita, M., Saito, H., and Ohya, Y. (2017) Yogurt consumption in infancy is inversely associated with atopic dermatitis and food sensitization at 5 years of age: A hospitalbased birth cohort study. J Dermatol Sci 86: 90-96.

Smith, P.M., Howitt, M.R., Panikov, N., Michaud, M., Gallini, C.A., Bohlooly-Y, M., et al. (2013) The microbial metabolites, short-chain fatty acids, regulate colonic Treg cell homeostasis. Science 341: $569-573$

Sommer, M.O. (2015) Advancing gut microbiome research using cultivation. Curr Opin Microbiol 27: 127-132.

Song, H., Yoo, Y., Hwang, J., Na, Y.C., and Kim, H.S. (2016) Faecalibacterium prausnitzii subspecies-level dysbiosis in the human gut microbiome underlying atopic dermatitis. $J$ Allergy Clin Immunol 137: 852-860.

Sonnenburg, J.L., Angenent, L.T., and Gordon, J.I. (2004) Getting a grip on things: how do communities of bacterial symbionts become established in our intestine? Nat Immunol 5: 569-573.

Steenbergen, L., Sellaro, R., van Hemert, S., Bosch, J.A., and Colzato, L.S. (2015) A randomized controlled trial to test the effect of multispecies probiotics on cognitive reactivity to sad mood. Brain, Behav, Immun 48: 258-264.

Sugaya, M. (2020) The role of Th17-related cytokines in atopic dermatitis. Int J Mol Sci 21: 1314.

Swidsinski, A., Weber, J., Loening-Baucke, V., Hale, L.P., and Lochs, H. (2005) Spatial organization and composition of the mucosal flora in patients with inflammatory bowel disease. J Clin Microbiol 43: 3380-3389.

Sztajer, H., Szafranski, S.P., Tomasch, J., Reck, M., Nimtz, M., Rohde, M., and Wagner-Döbler, I. (2014) Cross-feeding and interkingdom communication in dual-species biofilms of Streptococcus mutans and Candida albicans. ISME J 8: 2256-2271.

Tang, W.H., Wang, Z., Levison, B.S., Koeth, R.A., Britt, E.B., Fu, X., et al. (2013) Intestinal microbial metabolism of phosphatidylcholine and cardiovascular risk. $N$ Engl J Med 368: 1575-1584.

The Integrative HMP Research Network Consortium (2019) The Integrative Human Microbiome Project. Nature 569: 641-648.

Thompson, J.A., Oliveira, R.A., Djukovic, A., Ubeda, C., and Xavier, K.B. (2015) Manipulation of the quorum sensing signal AI-2 affects the antibiotic-treated gut microbiota. Cell Rep 10: 1861-1871.

Tissier, H. (1900) Etude sur la flore intestinale des normale nourrissons (Etat normal et pathologique). In Garré et Naud Paris. Recherches sur la Flore Intestinale des Nourrissons (état Normal et Pathologique). Paris: G. Carré et C. Naud.
Tomkovich, S., Dejea, C.M., Winglee, K., Drewes, J.L., Chung, L., Housseau, F., et al. (2019) Human colon mucosal biofilms from healthy or colon cancer hosts are carcinogenic. J Clin Invest 129: 1699-1712.

Tomkovich, S., Gharaibeh, R.Z., Dejea, C.M., Pope, J.L., Jiang, J., Winglee, K., et al. (2020) Human colon mucosal biofilms and murine host communicate via altered mRNA and microRNA expression during cancer. mSystems 5: e00451-19.

Tomova, A., Husarova, V., Lakatosova, S., Bakos, J., Vlkova, B., Babinska, K., and Ostatnikova, D. (2015) Gastrointestinal microbiota in children with autism in Slovakia. Physiol Behav 138: 179-187.

Toyofuku, M., Nomura, N., and Eberl, L. (2019) Types and origins of bacterial membrane vesicles. Nat Rev Microbiol 17: 13-24.

Tropini, C., Earle, K.A., Huang, K.C., and Sonnenburg, J.L. (2017) The gut microbiome: Connecting spatial organization to function. Cell Host Microbe 21: 433-442.

Turnbaugh, P.J., Ley, R.E., Mahowald, M.A., Magrini, V., Mardis, E.R., and Gordon, J.I. (2006) An obesity-associated gut microbiome with increased capacity for energy harvest. Nature 444: 1027-1031.

Tytgat, H.L.P., Nobrega, F.L., van der Oost, J., and de Vos, W.M. (2019) Bowel biofilms: Tipping ooints between a healthy and compromised gut? Trends Microbiol 27: 17-25.

Udayappan, S., Manneras-Holm, L., Chaplin-Scott, A., Belzer, C., Herrema, H., Dallinga-Thie, G.M., et al. (2016) Oral treatment with Eubacterium hallii improves insulin sensitivity in $d b / d b$ mice. NPJ Biofilms Microbiomes 2: 16009.

van de Wouw, M., Boehme, M., Lyte, J.M., Wiley, N., Strain, C., O'Sullivan, O., et al. (2018) Short-chain fatty acids: microbial metabolites that alleviate stress-induced brain-gut axis alterations. $J$ Physiol (Oxford, U K) 596: 4923-4944.

van Nood, E., Vrieze, A., Nieuwdorp, M., Fuentes, S., Zoetendal, E.G., de Vos, W.M., et al. (2013) Duodenal infusion of donor feces for recurrent Clostridium difficile. N Engl J Med 368: 407-415.

Venter, J.C., Remington, K., Heidelberg, J.F., Halpern, A.L., Rusch, D., Eisen, J.A., et al. (2004) Environmental genome shotgun sequencing of the Sargasso Sea. Science 304: 66-74.

Voelkerding, K.V., Dames, S.A., and Durtschi, J.D. (2009) Nextgeneration sequencing: from basic research to diagnostics. Clin Chem 55: 641-658.

Vogt, N.M., Kerby, R.L., Dill-McFarland, K.A., Harding, S.J., Merluzzi, A.P., Johnson, S.C., et al. (2017) Gut microbiome alterations in Alzheimer's disease. Sci Rep 7: 13537.

Wang, K., Liao, M., Zhou, N., Bao, L., Ma, K., Zheng, Z., et al. (2019a) Parabacteroides distasonis alleviates obesity and metabolic dysfunctions via production of succinate and secondary bile acids. Cell Rep 26: 222-235.e225.

Wang, M., Wan, J., Rong, H., He, F., Wang, H., Zhou, J., et al. (2019b) Alterations in gut glutamate metabolism associated with changes in gut microbiota composition in children with autism spectrum disorder. mSystems 4: e00321-18.

Wang, Z., Klipfell, E., Bennett, B.J., Koeth, R., Levison, B.S., Dugar, B., et al. (2011) Gut flora metabolism of phosphatidylcholine promotes cardiovascular disease. Nature 472: 57-63.

Watson, J.D., and Crick, F.H.C. (1953) Molecular structure of nucleic acids; a structure for deoxyribose nucleic acid. Nature 171: 737-738.

Weisburg, W.G., Barns, S.M., Pelletier, D.A., and Lane, D.J. (1991) 16S ribosomal DNA amplification for phylogenetic study. $J$ Bacteriol 173: $697-703$.

Wilson, M.R., Jiang, Y., Villalta, P.W., Stornetta, A., Boudreau, P.D., Carrá, A., et al. (2019) The human gut bacterial genotoxin colibactin alkylates DNA. Science 363: eaar7785.

Woting, A., Pfeiffer, N., Loh, G., Klaus, S., and Blaut, M. (2014) Clostridium ramosum promotes high-fat diet-induced obesity in gnotobiotic mouse models. mBio 5: e01530-14.

Wu, T.R., Lin, C.S., Chang, C.J., Lin, T.L., Martel, J., Ko, Y.F., et al. (2019) Gut commensal Parabacteroides goldsteinii plays a predominant role in the anti-obesity effects of polysaccharides isolated from Hirsutella sinensis. Gut 68: 248-262.

Yachida, S., Mizutani, S., Shiroma, H., Shiba, S., Nakajima, T., Sakamoto, T., et al. (2019) Metagenomic and metabolomic analyses reveal distinct stage-specific phenotypes of the gut microbiota in colorectal cancer. Nat Med 25: 968-976. 
Yang, J., Toyofuku, M., Sakai, R., and Nomura, N. (2017a) Influence of the alginate production on cell-to-cell communication in Pseudomonas aeruginosa PAO1. Environ Microbiol Rep 9: 239-249.

Yang, J.Y., Lee, Y.S., Kim, Y., Lee, S.H., Ryu, S., Fukuda, S., et al. (2017b) Gut commensal Bacteroides acidifaciens prevents obesity and improves insulin sensitivity in mice. Mucosal Immunol 10: 104116.

Yang, Y., Tian, J., and Yang, B. (2018) Targeting gut microbiome: A novel and potential therapy for autism. Life Sci 194: 111-119.

Ye, Z., Zhang, N., Wu, C., Zhang, X., Wang, Q., Huang, X., et al. (2018) A metagenomic study of the gut microbiome in Behcet's disease. Microbiome 6: 135 .

Yu, T., Guo, F., Yu, Y., Sun, T., Ma, D., Han, J., et al. (2017) Fusobacterium nucleatum promotes chemoresistance to colorectal cancer by modulating autophagy. Cell 170: 548-563.e516.
Zachariassen, L.F., Krych, L., Engkilde, K., Nielsen, D.S., Kot, W., Hansen, C.H., and Hansen, A.K. (2017) Sensitivity to oxazolone induced dermatitis is transferable with gut microbiota in mice. Sci Rep 7: 44385.

Zeng, M.Y., Inohara, N., and Nuñez, G. (2017) Mechanisms of inflammation-driven bacterial dysbiosis in the gut. Mucosal Immunol 10: $18-26$.

Zhao, L., Zhang, F., Ding, X., Wu, G., Lam, Y.Y., Wang, X., et al. (2018) Gut bacteria selectively promoted by dietary fibers alleviate type 2 diabetes. Science 359: 1151-1156. 